SHORT COMMUNICATION

\title{
RETROSPECTIVE STUDY ON LIVESTOCK VACCINE COVERAGE AND TRENDS IN DIGELU-TIJO DISTRICT, ARSI ZONE
}

\author{
Mulualem A. Endalew*, Fekadu S. Wakene \\ Ethiopian Institute of Agricultural Resarch ,Kulumsa Agricultural Research Center , Kulumsa Ethiopia.
}

\section{ARTICLE INFO}

\section{Article history}

Received: August 02, 2020

Revised: November 16, 2020

Accepted: December 23, 2020

\section{Keywords}

Vaccine coverage

Livestock species

Digelu-Tijo district

Retrospective data

\section{A B S T R A C T}

\begin{abstract}
Ethiopia has huge numbers of livestock hampered with high prevalence of infectious disease due to poor disease prevention and control. A five-year retrospective study was conducted to collect data on commonly diagnosed bacterial and viral disease and associated vaccine available at district government veterinary clinic in 2019 . The commonly encountered bacterial and viral cattle diseases recorded in the case record book were LSD, CBPP Black leg, Anthrax, Bovine pasteurellosis, and Mastitis. Sheep and goat pox disease, Ovine Pasteurellosis, PPR, CCPP, and anthrax were the common diseases of sheep and goat in the study district. Regarding diseases of poultry, New castle, Infectious Bursal Diseases (Gumboro), Infectious coriza, chicken pox, Coccidiosis, Fowl Typhoid, Fowl Cholera, and Marex are the major once. The commonly available vaccines in the study district were LSD, Black leg, Anthrax, Bovine pasteurellosis, Ovine pasteurellosis, Sheep and Goat Pox, PPR, and vaccine for chicken disease like New castle disease vaccine, Gumboro, Fowl Pox, Fowl typhoid and Fowl cholera were used. Vaccination coverage for Lumpy Skin Disease, Sheep and Goat pox and Newcastle viral diseases were good compared with other diseases. The majority $36 \%$ of the population of cattle were vaccinated for LSD in 2019 and the lowest $16 \%$ in 2015 .The lower portion of shoat $8 \%$ and half of the population $50 \%$ were vaccinated in 2017 and 2019 respectively. Maximum proportion of Newcastle and Gumboro vaccination coverage were $53 \%$ and $42 \%$. The vaccination trends for most of the vaccines were fluctuating from year to year whereas the vaccination trend for LSD was increasing from year to year.
\end{abstract}

Corresponding Author: Mulualem A. Endalew

Email: haamulualem6@gmail.com

(C) The Author(s) 2020.

\section{INTRODUCTION}

Ethiopia is known to be the first in livestock population in Africa and 10th in the world with 59.5 million heads of cattle, 30.70 million sheep, 30.2 million goat, 2.16 million horses, 8.44 million donkeys, 0.41 million mules, 1.21 million camels and 56.53 million poultry (Authority, 2019). Oromia region is one of the livestock potential regions which consists the largest livestock population in Ethiopia. The numbers of livestock species of the region are estimated to be 24,1 million head of cattle 9.8 million sheep,8.1 million goat,1.2 million horse, 140,114 mules, 3.4milion donkey, 299,422 camel and 20,4milion poultry. Arsi Zone is one of the livestock potential Zones of the Region with estimated livestock population of 2.5 million cattle, 1.5 million sheep, 789,864 goats, 276,767 horses, 28,658 mules, 509,410 donkey, 52,853 camels and 2 million poultry. Diseases can directly or indirectly affect livestock production 
which resulted in food insecurity, food safety, trade ban, rural development, and the environment, while also affecting the livelihood of farmers (EU, 2012).

In Ethiopia, animal diseases are rampant in all agroecological zones of the country and are exerting both direct and indirect damages to the livestock industry in particular and national economy in general. There is high morbidity and mortality of chicken with the overall mortality of $56.8 \% 50 \%$ and $43.8 \%$ in Ethiopia, Oromia and Arsi Zone respectively ((CSA), 2017). Ethiopia is unable to enter into lucrative international markets of livestock and livestock products because of the presence endemic and trans boundary livestock disease which cannot adhere to the international standards, guidelines and recommendations established by the OIE mainly the rights and obligations set out by the World Trade Organization (WTO) under the Agreement on Sanitary and Phytosanitary (SPS) trad standards in animals and animal products (Thiermann, 2005). According to (Yearbook, 2011), and (Gizaw et al., 2020) report, the major diseases of ruminants in Ethiopia so far reported and highly prevalent are foot and mouth disease, LSD, Anthrax, black leg, bovinepasteurelosis, CBPP, Bovinetuberculosis, bovine brucellosis, bovinecysticercosis, toxoplsmosis, salmonellosis, mastitis, sheep and goat pox, camel pox, CCPP, Ovine pasteurelosis external and internal parasites. Regarding chicken diseases, Newcastle disease, Gumboro, Fowl Pox, Fowl Cholera, Fowl Typhoid and Coccidiosis are highly prevalent and economically important diseases in Ethiopia.

Fulfilling the international animal health and food safety standards has been a challenge for many countries including Ethiopia. This is due to the fact that infectious and zoonotic diseases intersect with the realities of porous borders and are exacerbated by the unusable agricultural, economic, and political systems prevailed in such environments. Furthermore, due to the widespread animal diseases, the productivity and production efficiency of livestock species is greatly affected and the public is also at risk of contracting by any of the endemic zoonotic diseases. Thus, to mitigate the ever-increasing trends of disease threats posed to the animal agriculture and public health risks, vaccinating livestock is one of the cost-effective prevention methods currently available and practiced in both animals and humans.

Vaccination is widely recognized as one of the most efficient tools for animal and public health, showing obsessions cost-benefit advantages for all the target population involved. In spite of the global availability of vaccines for many of the animal diseases, the veterinary vaccines present in Ethiopia are of few in number and lowest in vaccination coverage.

Availability of vaccine in Ethiopia: National Veterinary Institute in Ethiopia has been producing about 21 kinds of vaccines which play a crucial role in improving the health of the country's livestock resource. There are 7 bacterial and 9 viral veterinary vaccines available at the national veterinary institute (NVI), which is the only vaccine manufacturer and supplier of the country, Ethiopia (MoA, 2011). Information on the vaccine coverage and trends is lacking at country level in general and in the study areas in particular. Studies conducted in the northern parts of Ethiopia on sheep and goat vaccine coverage which varies on the vaccine types and year to year. The highest vaccination coverage was reported on PPR and sheep and goat pox vaccine and the lowest coverage on ovine anthrax and pasteurellosis vaccine coverage. In addition, review report on veterinary service delivery system in Ethiopia indicated about low veterinary service including vaccination. Shortage of vaccines, lack of transport, refrigerator at veterinary clinic, poor awareness of the farmers regarding importance of vaccine were the major determining factors for vaccination service delivery (Hooper, 2016). Vaccine coverage in the central highland regions of the country is not known. Thus, this study was initiated to assess the vaccination coverage and trends of vaccination for five years from 2015-2019.

\section{METHODODOLOGY}

\section{Study area and data collection}

The study was conducted in Digelu-Tijo district located in the southern part of Arsi Zone from February 21/2020 to April 2020. Datasheet were prepared for retrospective data collection and administered to be filled by Veterinary experts at the study clinics. A fiveyear retrospective data on numbers of cattle, chicken, sheep and goat regardless of age, breed and sex of animals and vaccine types used for the last five years for the selected disease were filed by veterinary experts at the district veterinary clinic which is situated at the district town. It is public veterinary clinic which can serve to the farmers in and around Sagure town.

\section{Data entry and analysis}

The collected retrospective data were entered in 
Microsoft excel and descriptive statistics were used for data analysis. Vaccination coverage was calculated by dividing the number of animal species vaccinated divided by numbers of animal species registered per year. Bar chart and line graphs were used to represent the analysis result.

\section{RESULTS}

The types and vaccine coverage in cattle, sheep, goat and chicken species were described under the figures below. The vaccination coverage for lumpy skin disease increases from year to year $15.8 \%$ in 2015 to $36 \%$ in 2019. The lower $4 \%$ of vaccination coverage were recorded for black leg in 2015 and 2019 (Figure 1).

Only three vaccines were used in the study district veterinary clinic even though various sheep and goat diseases were prevalent in the area. Among available sheep and goat vaccines, Sheep and Goat pox vaccine had good coverage $30.7 \%$ in 2015 to $50 \%$ in 2019 compared with other sheep and goat vaccines (Figure 2).

There were four types of chicken vaccines used in the study district with various coverage ranges. Among those vaccines, Newcastle vaccine has good coverage $19.9 \%$ to $53 \%$ than the other poultry vaccines whereas the lowest $4 \%-6 \%$ of vaccine coverage were done for Gumboro disease starting from 2015-2018. The vaccine coverage of Gumboro disease abruptly increased to $41 \%$ in 2019 because of the occurrence of the disease outbreak in the study district (Figure 3).

Vaccination trends in Digelu Tijo district from 20152019

Vaccination trends of lumpy skin disease in cattle, was increasing from 2015-2019 in Digelu Tijo district whereas the trend of chicken vaccine, sheep and goat were fluctuating from year to year (Figure 4-6).

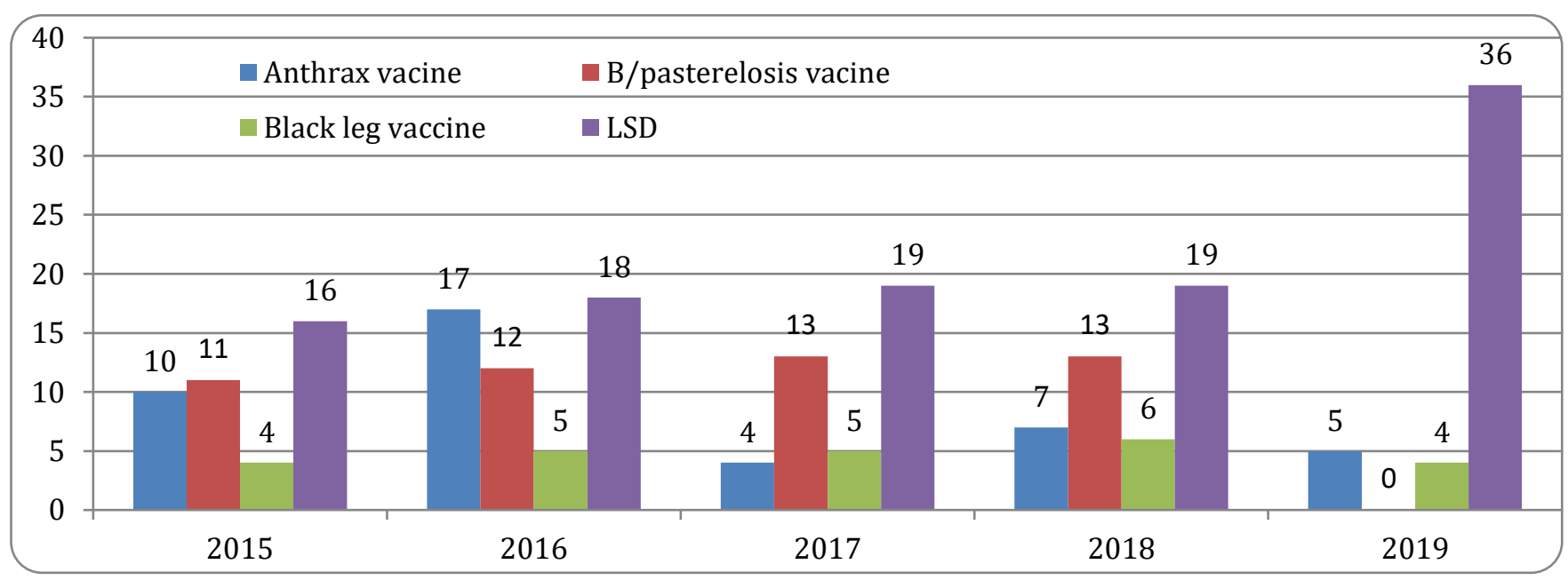

Figure 1. Cattle \% vaccine coverage in Digelu-Tijo district from 2015-2019.

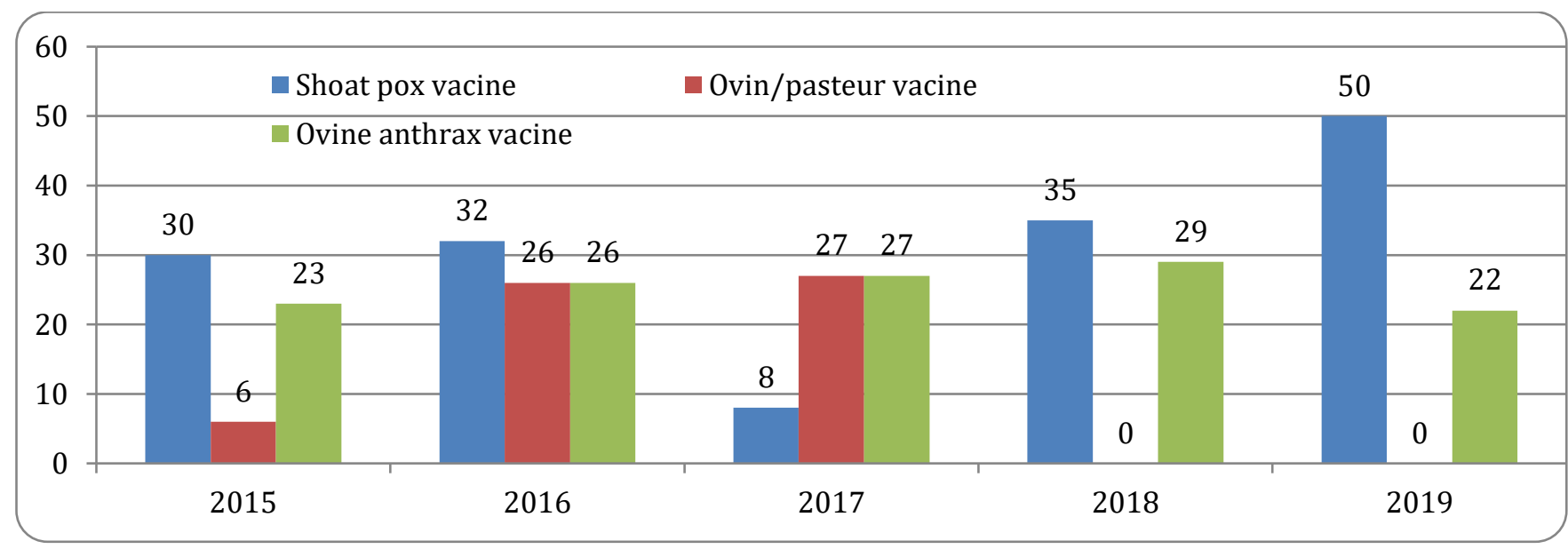

Figure 2. Sheep and goat \% vaccine coverage in Digelu-Tijo district from 2015-2019. 


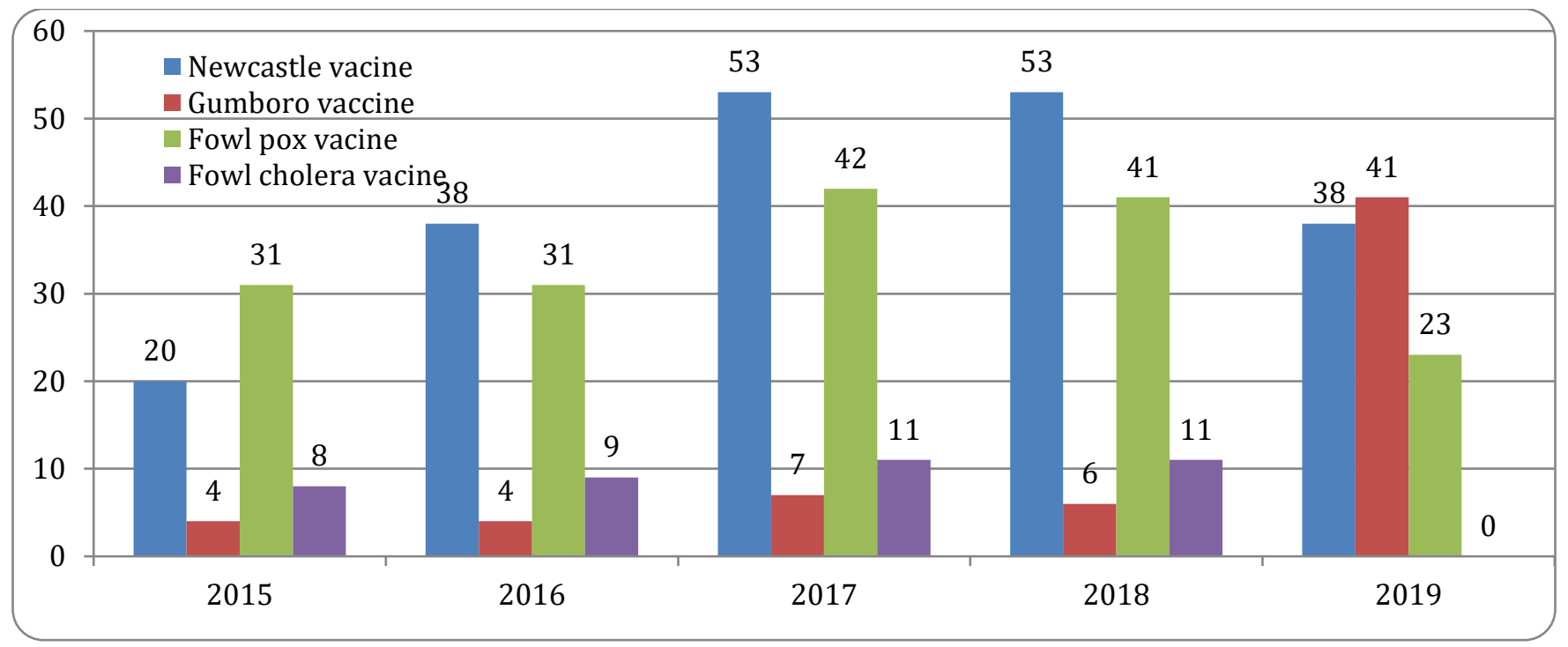

Figure 3. Chicken vaccine \% coverage in Digelu-Tijo District from 2015-2019.

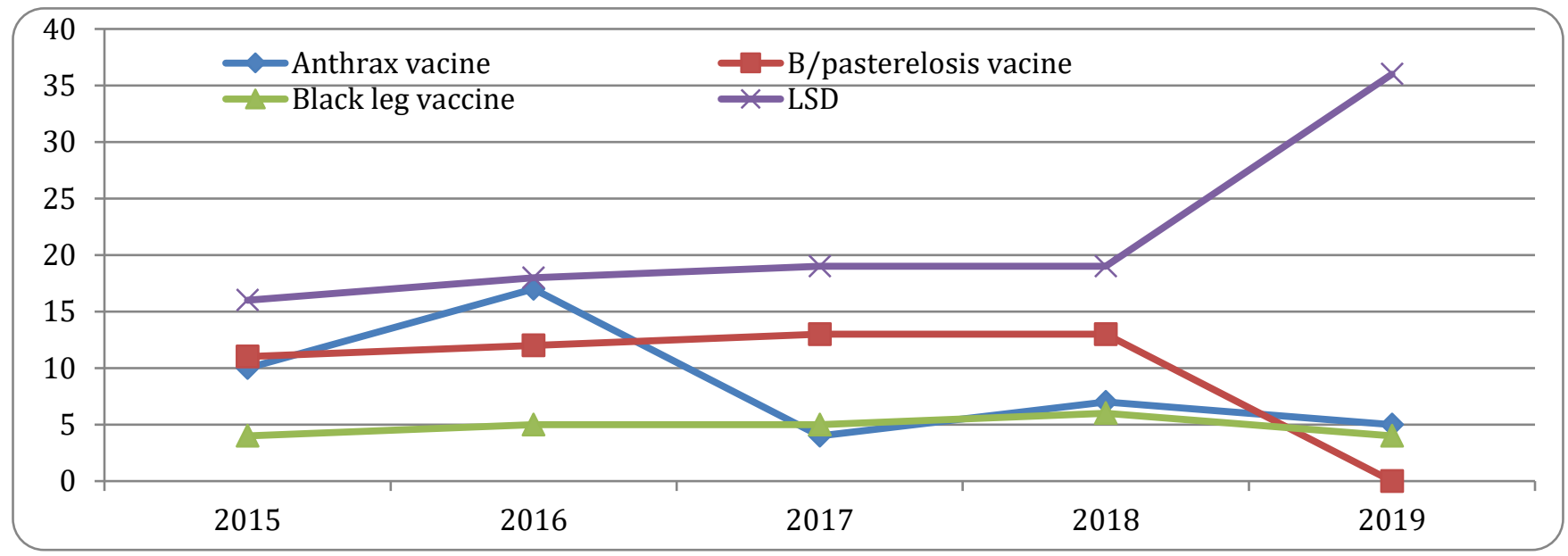

Figure 4. Cattle vaccination trends in Digelu-Tijo district from 2015-2019.

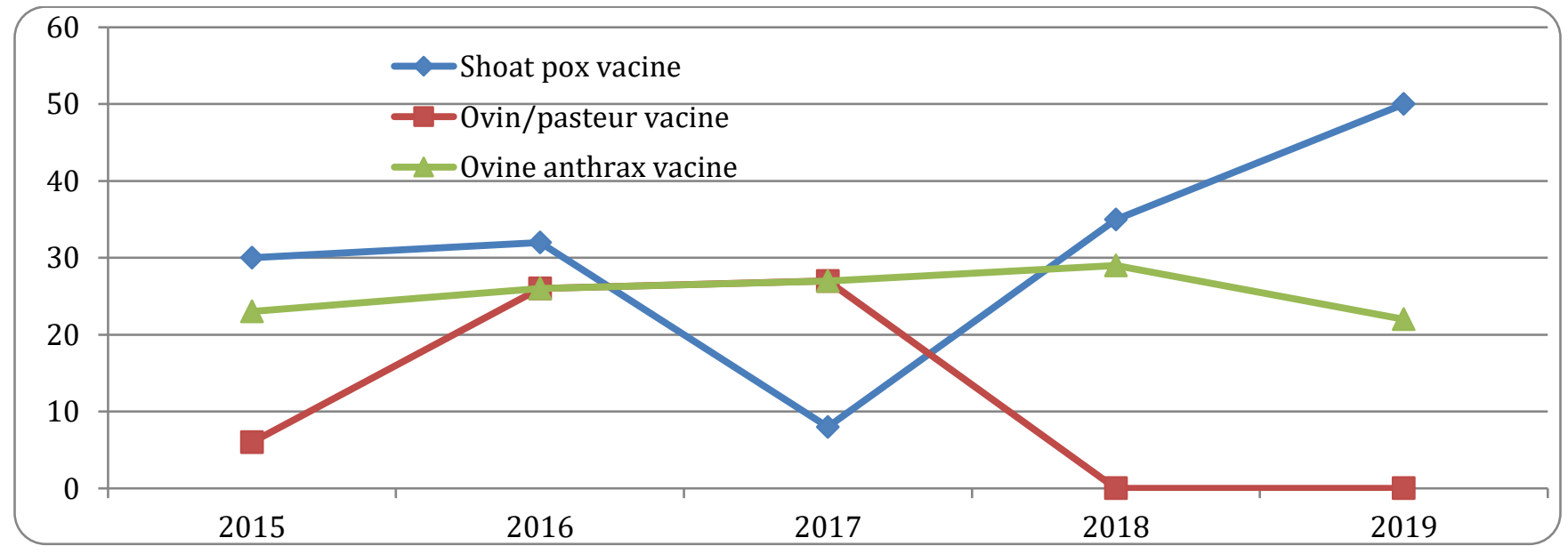

Figure 5. Sheep and goat vaccination trends in Digelu-Tijo district from 2015-2019. 


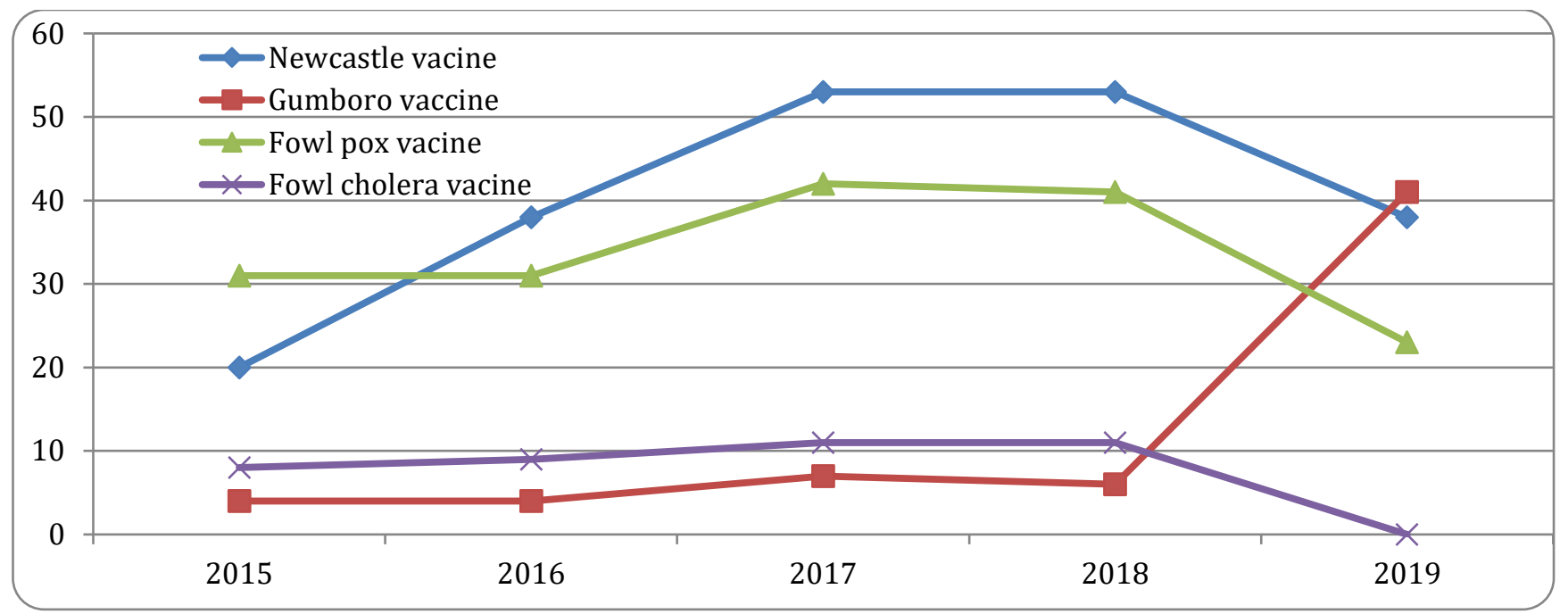

Figure 6. Chicken vaccination trends in Digelu-Tijo district from 2015-2019.

\section{DISCUSSION}

The most common livestock diseases in the study districts were; lumpy skin disease, black leg, Anthrax, Mastitis, External and Internal Parasites, Striptotricosis, Actionbacillosis, Sheep and Goat pox and Pasteurelosis. From those common diseases, vaccines for LSD, Black leg, Bovine Pasteurelosis, Anthrax for Cattle and Ovine Pasteurelosis, Sheep and Goat Pox vaccines were used in the study district. Regarding chicken vaccines; Newcastle, Fowl Pox, Fowl Cholera, Infectious bursal (Gumboro) vaccines were used for the prevention and control of chicken disease in the study area. The vaccine coverage in general is very poor compared with the livestock population which is similar with (Hailu and Aferu, 2015; Tadege and Afera, 2016), which was conducted in Tigray Region Northern Ethiopia. The vaccine coverage of Anthrax in cattle was very low $17 \%$ compared with other vaccine cover and the remaining $83 \%$ of the population did not cover during mass vaccination. Contrasting to our finding (Sarker et al., 2020) which were conducted in Bangladesh $44 \%$ of the cattle were covered in mass vaccination campaign.

There are two types of vaccination campaign for cattle, sheep and goat diseases in the study district which were practiced during diseases out break and seasonally occurring endemic and pandemic list A and B disease. The vaccination trend for all of the vaccine types in each species of animals' is fluctuating because there is no planed disease control strategy. Vaccine purchase and vaccination of animals is conducted based on occurrence of disease outbreak except diseases of chicken vaccine. The vaccination service for list A diseases were subsidized to be given free of charge. The prices of vaccination service for list $B$ diseases per dose ranges from 0.35 cents to 1.50 Eth birr. From the retrospective data we can conclude that lumpy skin disease from cattle species, sheep and goat pox diseases from small ruminants and Newcastle disease virus for poultry are the most important viral diseases in the study district.

\section{ACKNOWLEDGEMENTS}

The author would like to Acknowledge Digelu-Tijo District Bureau of Agriculture and Veterinary clinic for their cooperation during the retrospective data collection.

\section{REFERENCES}

(CSA), C.S.A., 2017. Statistical Report on Livestock and Livestock Characteristics (Private Peasant Holdings), Statistical Bulletin 587, Addis Ababa.

Authority, C.S., 2019. The Federal Democratic Republic of Ethiopia Central Statistical Agency, Agricultural Sample Survey, Report On Area And Production Of Major Crops, Ethiopia.

EU, 2012. A decade of EU-funded Animal Health Research, European Union, Luxembourg.

Gizaw, S., Desta, H., Alemu, B., Tegegne, A., Wieland, B., 2020. Importance of livestock diseases identified using participatory epidemiology in the highlands of Ethiopia. Tropical Animal Health and Production 52, 1745-1757.

Hailu, G., Aferu, B., 2015. Retrospective Assessment of Black Leg in Kafta Humera Woreda. Momona Ethiopian Journal of Science 7, 134. 
Hooper, P., 2016. Review of animal health service delivery in the mixed crop-livestock system in Ethiopia. International Livestock Research Institute (ILRI), Nairobi, Kenya.

MoA, 2011. Ethiopia Animal Health Yearbook. Ministry of Agriculture Animal and Plant Health Regulatory Directorate, Addis Ababa, Ethiopia.

Sarker, M.S.A., El Zowalaty, M.E., Shahid, M.A.H., Sarker, M.A., Rahman, M.B., Järhult, J.D., Nazir, K.H.M.N.H., 2020. Maximization of Livestock Anthrax Vaccination Coverage in Bangladesh: An
Alternative Approach. Vaccines 8, 435.

Tadege, A., Afera, B., 2016. Assessment of Vaccination Coverage of Sheep and Goat using Retrospective Data in Woreda Raya Alamata. Momona Ethiopian Journal of Science 8, 83.

Thiermann, A.B., 2005. Globalization, international trade and animal health: the new roles of OIE. Preventive Veterinary Medicine 67, 101-108.

Yearbook, P.A.H., 2011. Interafrican Bureau for Animal Resources African Union, Nairobi,, Kenya.

Publisher's note: EScience Press remains neutral with regard to jurisdictional claims in published maps and institutional affiliations.

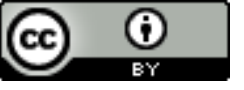

Open Access This article is licensed under a Creative Commons Attribution 4.0 International License, which permits use, sharing, adaptation, distribution and reproduction in any medium or format, as long as you give appropriate credit to the original author(s) and the source, provide a link to the Creative Commons license and indicate if changes were made. The images or other third-party material in this article are included in the article's Creative Commons license, unless indicated otherwise in a credit line to the material. If material is not included in the article's Creative Commons license and your intended use is not permitted by statutory regulation or exceeds the permitted use, you will need to obtain permission directly from the copyright holder. To view a copy of this license, visit http://creativecommons.org/licenses/by/4.0/. 